\title{
Comparative reproductive function in cervids: implications for management of farm and zoo populations
}

\author{
G. W. Asher ${ }^{1}$, S. L. Monfort ${ }^{2}$ and C. Wemmer ${ }^{2}$ \\ ${ }^{3}$ AgResearch, Invermay Agricultural Centre, Private Bag 50034, Mosgiel, New Zealand; \\ ${ }^{2}$ National Zoological Park, Conservation and Research Center, Smithsonian Institution, \\ Front Royal, VA 22630, USA
}

\begin{abstract}
The cervids represent a complex assemblage of taxa characterized by extreme diversity in morphology, physiology, ecology and geographical distribution. Farmed species (for example red deer and fallow deer) are usually the common larger-bodied, gregarious and monotocous species that express marked reproductive seasonality in their temperate environment. Their commercial importance has facilitated considerable research into reproductive physiology and the development of assisted reproductive technologies (ART). In contrast, the remaining species, including many of tropical origin, show wide diversity in reproductive patterns, have generally received little scientific scrutiny, and include a number of endangered taxa that are reliant on ex situ conservation efforts (such as captive breeding) to ensure their survival. Domestication and ex situ management programmes have been associated with widespread translocation of various cervid species around the world, often placing the animals in environments that are not compatible with their evolved reproductive patterns. For example, the summer calving/lactation pattern of red deer, attuned to northern continental climatic patterns, is frequently misaligned with seasonal changes in feed availability in the Australasian pastoral environment. Similarly, seasonal or aseasonal calving patterns of tropical species translocated to temperate regions are usually associated with increased perinatal mortality of calves born in cool seasons. Conversely, temperate species in tropical zones may exhibit aberrant reproductive patterns in the absence of biologically significant photoperiod fluctuations. ARTs, which presently include artificial insemination, embryo transfer and in vitro embryo production, have potential application to the genetic management and population growth of various cervid species. Although application to some farmed cervid species is widespread, these technologies are rarely directly transferable from farmed to endangered species. Even within species, ART protocols developed successfully for one genotype (i.e. subspecies) may be ineffective in another (for example superovulation of red deer and wapiti). Therefore, application to genetic management of endangered species necessitates prior research into their reproductive patterns. This is often difficult because of the rarity of the animals, a lack of suitable handling facilities for the particular species, and the timid nature of the deer. More recently, however, non-invasive reproductive profiling, based on remote collection and monitoring of excreted steroid metabolites, has facilitated such research.
\end{abstract}

\section{Introduction}

The 'cervids' include 43 species and 206 subspecies (Whitehead 1993) characterized by extreme diversity in morphology, physiology, ecology and geographical distribution. It is important to recognize that in any consideration of reproductive function no one species represents a 'typical' 
deer. For example, some cervids exhibit highly seasonal patterns of births in cool temperate climes, while others are completely aseasonal in equatorial regions. Furthermore, many species are strictly monovular and bear single offspring annually, whereas others are normally polyovular and bear multiple offspring. Even embryonic development and placentation vary considerably among species (Lincoln, 1985).

An increased understanding of reproductive function in cervids over the last few decades stems largely from the growing importance of various deer species in agriculture (for example deer farming) and ex situ conservation efforts (for example captive breeding of endangered species). In general, the research has been directed towards successful application of assisted reproductive technologies to manipulate the genetic constitution of populations (for example selection for improved agricultural productivity; avoidance of inbreeding depression in captive populations) or to increase rates of propagation of specific genetic lineages. However, we emphasize the fact that studies to date have focused on a few key species that do not necessarily reflect the full range of cervid physiology.

The international deer farming industry is based broadly on one of two groups of cervids: those of cool temperate northern origin such as European red deer (Cervus elaphus spp scoticus, hippelaphus), North American and Asiatic wapiti (Cerous elaphus spp nelsoni, roosevelti, manotobensis, xanthopygus), European fallow deer (Dama dama) and Asiatic sika deer (Cervus nippon); and those of tropical equatorial origin such as chital deer (Axis axis), rusa deer (Cervis timorensis) and sambar deer (Cerous unicolor). All tend to be genotypes that exhibit notable gregariousness (cf numerous highly territorial species that live solitary lives) and are adapted to mixed browsing/grazing (cf species that are highly selective browsers). Farmed species, typically, can adjust to exclusive grazing and open-range environments even though they probably evolved to live on the forest-pasture interface. In these respects, they represent a specific subset of the entire cervid genome biased towards the larger-bodied, monovulatory species with a high degree of behavioural plasticity. They also represent species that have remained relatively common in the wild.

In contrast, a significant proportion of cervid species have not survived particularly well over the last few centuries. The 1996 IUCN Red List of Threatened Animals identifies approximately 20 species of cervid, representing nine genera, that are either threatened or endangered with extinction world-wide. Species decimated by over-hunting and habitat destruction are often reliant on ex situ conservation (ie captive breeding) for any chance of survival. A number of species, such as Pere David's deer (Elaphurus davidanus), Mesopotamian fallow deer (Dama dama mesopotamica) and Eld's deer (Cerous eldi eldi), are represented almost entirely by captive individuals or intensively managed populations. The relevance of captive populations to conservation increases as the risk of extinction increases in in situ populations. Several threatened species of deer have internationally registered studbooks, which facilitate demographic and genetic management. These programmes continue without linkage to in situ conservation, but nonetheless augment the ability of conservationists to respond to emergencies, should wild populations diminish to critical numbers or become victims of stochastic events. Reproductive management strategies for such species are focused primarily in two areas: first, optimizing reproductive performance within artificial habitats and, second, judicious genetic management to reduce the impact of inbreeding. Traditional captive breeding/management programmes for wild ungulates often have failed to integrate even regional zoological collections into 'single' populations for genetic and demographic management. However, traditional husbandry-management techniques now can be combined with reproductive biotechnology, including germplasm cryopreservation and assisted reproductive technologies (ART) to ensure sufficient genetic diversity without exceeding limited captive animal holding space in zoos (Wildt $e t$ al., 1997). With the use of modern management principles, preferred pairings can be co-ordinated by genetic specialists to facilitate natural breedings when feasible, and ART when most practical to avoid long-distance and expensive transport of individual animals. Although this approach does not come without substantial costs in terms of time, energy and expense, the long-term rewards hold the promise for (1) stabilizing the number of captive animals, (2) improving genetic diversity, and (3) establishing viable genome resource banks (GRB) for frozen germplasm. It is interesting to note that while farmed deer species represent a biased 'type' of cervid, captive breeding programmes are in 
place for a wide range of cervid 'types'. Reproductive management principles and specific technologies developed for the farmed species are, therefore, not always applicable to captive breeding programmes for endangered species. A notable example would be ex situ conservation of pudu (Pudu sp) and muntjac (Muntincus sp), both being small-bodied, solitary, forest-dwelling taxa.

\section{Seasonality of Reproduction}

The necessity for most cervid species to give birth at an appropriate time of year for optimal survival and growth of offspring has exerted considerable influence on their reproductive physiology (Lincoln and Short, 1980). Species of northern temperate origin typically conceive in autumn and calve in summer, whereas species of tropical origin often exhibit limited seasonality or are completely aseasonal (Lincoln, 1985). The endogenous mechanisms governing seasonal reproductive patterns in temperate species are robust, being manifest rigorously when animals are transferred between localities despite subtle regional variations in seasonal feed supply. Furthermore, transference across the equator results in an exact 6 month phase change (Marshall, 1937), even though the relationship between season and feed production differs considerably between continental northern hemisphere and insular southern hemisphere environments (Asher $e t$ al., 1993a). Tropical species transferred from equatorial $\left(0-15^{\circ}\right)$ zones may exhibit either pronounced 'reverse seasonality' (i.e. spring conceptions and autumn/winter calving, for example Eld's deer), wide breeding seasons (i.e. calving mostly spread over 3-6 months of the year; for example chital deer in Australia) or complete aseasonality (i.e. calving year round; for example Reeve's muntjac) (Chapman et al., 1984; Loudon and Curlewis, 1988; Monfort et al., 1991; Mylrea, 1992). It should be noted, however, that there is a general paucity of information on the birth season of tropical species in their native tropical environment (Lincoln, 1985).

It is generally accepted that entrainment of seasonal reproductive cycles is effected by endogenous recognition of photoperiodic changes, with the majority of temperate species initiating mating activity during decreasing daylength of late summer and autumn (Lincoln and Short, 1980). Variations in the actual mating season between species of up to 8 weeks usually offsets genetically determined species differences in duration of gestation, such that parturition generally occurs in mid-summer (Lincoln, 1985). A notable exception amongst temperate species is the Pere David's deer, which initiates mating activity in early summer and calves in late spring despite an unusually long gestation of about 280 days (Wemmer ef al, 1989; Monfort et al, 1991). There is growing evidence that some tropical species may also perceive, and respond to, changes in photoperiod, although in a markedly different manner than temperate species. For example, rusa deer living in the tropics do not exhibit well-synchronized antler cycles and reproductive seasons, indicating that photoperiod does not effectively modulate reproductive seasonality (van Mourik and Stelmasiak, 1990). Because rusa deer probably migrated from outside the tropical zone, it has been suggested that, once translocated to temperate latitudes, they re-established an evolutionarily-based 'long-day' reproductive rhythm (van Mourik and Stelmasiak, 1990). Although Eld's deer exhibit strong reproductive seasonality in their subtropical native range, this pattern persists after translocation to temperate latitudes $\left(48^{\circ} \mathrm{N}\right.$ latitude), even though this strategy results in the birth of offspring during the harsh winter months (Monfort et al., 1991). The persistence of such an apparently maladaptive strategy indicates that there is an endogenous rhythm linked to its adaptive significance in their native sub-tropical habitat. Alternatively, Eld's deer may respond to the relatively subtle low amplitude photoperiodic oscillations experienced in their native sub-tropical latitudes; translocation to a temperate latitude may simply serve to reinforce or strengthen seasonal rhythms because the direction of photoperiodic change is similar and the amplitude of seasonal daylength changes is more pronounced. Similarly, treatment of chital deer stags with exogenous melatonin has been shown to hasten antler casting (Mylrea, 1992), indicating possible photoperiodic responsiveness in a species considered to exhibit limited seasonality in both tropical and temperate environments (Loudon and Curlewis, 1988). In contrast, however, tropical sambar deer acclimatized to temperate zones in New Zealand exhibit a loose pattern of 'reverse seasonality' in calving but fail to show any 
appreciable seasonal patterns in prolactin secretion (Asher et al, 1997a). Thus, some tropical species may not perceive photoperiodic cues, if they are perceived at all, in the same manner as their temperate relatives. Because tropical cervid species are not exposed to strong circannual photoperiodic rhythms, reproductive patterns may have evolved in response to a variety of factors including (1) seasonal fluctuations in the availability of specific food items, (2) local resource competition among sympatric species, or (3) predation pressures; and many of these factors may be directly related to rainfall patterns. For example, predation might increase during seasons when adequate cover is unavailable. Alternatively, selective pressures in some species may have acted more strongly on the ability to conceive rather than on the timing of the birth season; in such cases, optimal forage availability might be predicted during the mating season rather than the birthing season.

Several studies have demonstrated a relationship between annual rainfall patterns and timing of the fawning season of sub-tropical and tropical deer species. It has been asserted that conceptions are timed in white-tailed deer (Odocoileus virginianus) living in Columbia ( $5^{\circ} \mathrm{N}$ latitude) and the Everglades National Park $\left(25^{\circ} \mathrm{N}\right.$ latitude) so that births occur during the dry season, which may reduce mortalities associated with the inability of the neonate to thermoregulate properly under wet conditions (Blouch, 1987; Smith et al., 1996). The fawning season in hog deer (Axis porcinus, $27^{\circ} \mathrm{N}$ latitude, Nepal) coincides with new vegetative growth that occurs after seasonal grass fires caused by lightning strikes or agricultural burning, believed to have been occurring for thousands of years (Mishra and Wemmer, 1987). Although other tropical species including red brocket deer (Mazama americana, $4-6^{\circ} \mathrm{N}$ latitude, Suriname) also have fawning seasons that coincide with the end of the rainy season (Branan and Marchinton, 1987), others such as pampas deer (Ozotocerso bezoarticus bezoarticus; $18^{\circ} \mathrm{S}$ latitude, Argentina) and sambar deer ( $27^{\circ} \mathrm{N}$ latitude, Nepal) exhibit peak fawning during the wet season (Jackson and Langguth, 1987; Mishra and Wemmer, 1987, respectively). Even species like the sambar deer and chital deer sharing the same habitat $\left(27^{\circ} \mathrm{N}\right.$, Nepal) fawn 6 months out-of-phase to one another (Mishra and Wemmer, 1987). Thus, no clear pattern emerges to explain the variance in reproductive patterns exhibited by tropical cervids.

It is precisely this lack of reproductive uniformity among sympatric species from which we can infer differing adaptations to the environment based on a variety of regulatory mechanisms. In Nepal's Royal Chitawan National Park $\left(27^{\circ} \mathrm{N}\right.$ latitude) four deer species co-exist, including two browsers (sambar deer and muntjac), one grazer (hog deer) and one mixed feeder (chital deer) (Mishra and Wemmer, 1987). Within these guilds each species differs in annual reproductive cycle, habitat selection and feeding ecology. Although the muntjac deer breeds all through the year, the birth season of the sambar deer coincides with the onset of the monsoon; hog deer give birth when new grasses flush after burning, and chital give birth during the dry season. Although photoresponsiveness in tropical cervid species may persist as an evolutionary relic from a time when this trait was advantageous to survival, the tight linkage between photoperiod and seasonal reproduction observed in temperate species may not completely explain the existence of reproductive seasonality in many tropical species. It is important to recognize that we know little about the factors that govern reproductive rhythms in tropical cervid species, and even less about how reproduction is adapted to the ecological setting in which it evolved. Further studies are needed to determine whether tropical cervid species are truly photoresponsive. In addition detailed studies of tropical cervids in native environments are important for determining the impact of uniform photoperiod, seasonal rainfall patterns and food availability on reproductive seasonality.

\section{Implications of Seasonality for Farmed Deer Productivity}

Red deer/wapiti (Cervus elaphus spp) and fallow deer represent the main species farmed in temperate environments in Australasia, North America and Europe. Both species have reproductive patterns attuned to the northern continental environment. Their autumn mating-summer calving pattern has been strictly conserved when the species have been transferred to the southern hemisphere. Such reproductive seasonality has obvious beneficial consequences for the species 
within their traditional environment. However, translocation to more temperate, insular Austral environments has been associated with a degree of misalignment between reproductive seasonality and seasonal changes in feed availability (reviewed by Asher et al., 1993a). For example, the spring flush of growth of high quality pasture can occur as early as August-October in the northern regions of New Zealand, yet farmed red deer calve naturally in November-December. Their peak lactational demands and the demands of the young calf for high quality feed are in January-March, when the pasture growth rate and quality are limiting because of seasonal moisture deficits and natural pasture senescence. The challenge for deer farmers is to meet the high energy demands of the lactating female and the calf during such periods. The consequences of failing to do so include increased calf mortality, decreased calf growth rates and depressed hind liveweights. This may further impact on ovulatory activity of the females in the subsequent breeding season. Srategies for reducing the possible impacts of such misalignment include (i) shifting the seasonal peak of pasture growth by using different pasture cultivars or by preventing reproductive senescence of grasses; (ii) selecting deer genotypes with the genetic propensity to calve earlier; and (iii) artificially manipulating the reproductive seasonality of the breeding herd (reviewed by Asher et al., 1993a).

Uncontrolled breeding management of tropical species in temperate zones creates a number of production problems. First, and perhaps most obvious, is the high mortality of neonates born in winter, for example with rusa deer farmed in the southern latitudes of Australia (van Mourik, 1986). Second, predation of neonates has greater overall impact on unsynchronized herds owing to the higher predator:prey ratio than in herds with concise calving patterns (i.e. prey sativation), as exemplified by fox predation of chital deer fawns in Australia (Mylrea, 1992). Generally, however, judicious control of male:female joining dates allows tight control of the season and synchrony of births of tropical species in seasonal environments. Such easy options are not available for temperate species.

There have been recent attempts to establish temperate species, such as red deer and fallow deer, in equatorial zones (despite the presence of locally adapted cervid species). Anecdotal evidence indicates that removal of photoperiodic signals has had a marked effect on the overall physiology of these deer. For example, fallow deer translocated from New Zealand to southeast Asia exhibited apparent 'de-synchronization' to the extent that $70 \%$ of does become anovulatory at the time of joining during their 'normal' breeding season. This situation was subsequently corrected by strategic administration of melatonin implants for periods of $2-3$ months. The bucks maintained a high within-herd synchrony in their antler cycles with or without melatonin treatment (G Christie, personal communication, 1993).

Seasonal (or aseasonal) constraints encountered in extensively managed farmed populations are seldom considered important in zoo populations owing to high levels of attention given to individuals and the provisions made for intensive feeding and housing. However, many zoo populations consist of non-native species that are maladapted to local climates. Inappropriate birth seasons (for example winter fawning of Eld's deer in North American zoos) can lead to high neonatal mortality due to the inability of the fawn to thermoregulate appropriately (Monfort et al., 1993a).

\section{Ovulatory Cycle}

With few exceptions, female cervids are polyoestrous, and non-pregnant animals are capable of exhibiting either continuous oestrous cycles (for example some tropical species) or, more commonly, alternating periods of oestrous cyclicity and anoestrus (Fig. 1). Oestrous cycles have been characterized for a number of species from studies on oestrous behaviour and luteal secretion of progesterone. In non-pregnant females of temperate species, such as red deer and fallow deer, the onset and termination of oestrous cyclicity occur in autumn and spring respectively, with 5-8 cycles expressed. Anoestrus is characterized by low concentrations of progesterone indicative of complete ovulatory arrest, and may persist for 4-6 months from spring to early autumn (Fig. 1). In marked contrast, the tropical brow-antlered Eld's deer initiates oestrous cycles in spring and enters 


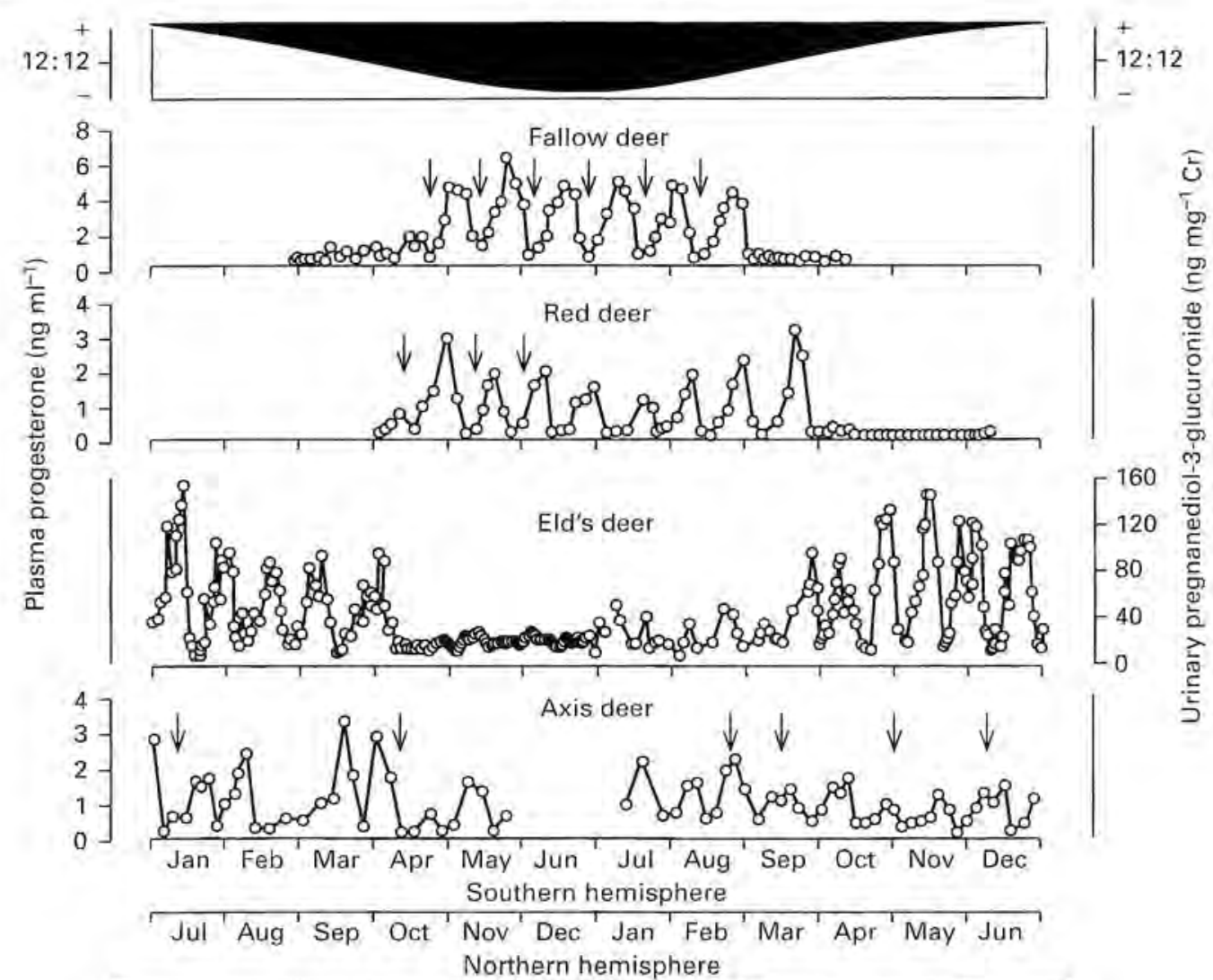

\begin{tabular}{l|l|l|l|l}
\hline & Autumn & Winter & Spring & 3 \\
\hline
\end{tabular}

Fig. 1. Oestrous/luteal cycles in temperate (fallow, red) and tropical (Eld's, axis) species of deer in temperate environments, as defined by peripheral plasma progesterone concentrations or urinary pregnanediol metabolite concentrations during the annual cycle of non-pregnant females. The data have been normalized about common hemispheres and placed in relation to relative annual changes in photoperiod. Arrows indicate overt oestrous behaviour (data from Asher, 1985; Asher and Fisher, 1991; Monfort et al, 1991; Mylrea, 1992).

anoestrus in the following autumn in temperate regions, this being effectively a 6 month phase shift from temperate species (i.e. 'reverse seasonality'). Studies on tropical axis deer in temperate regions of Australia indicate oestrous cyclicity throughout the year (Fig. 1), although success of artificial oestrous synchronization techniques appears to vary with season (Mylrea, 1992).

The transition into the breeding season is characterized by 'silent ovulations' (i.e. ovulations not preceded by overt oestrus) and short-lived ( $8-10$ days) corpora lutea in most cervid species studied (Thomas and Cowan, 1975; Asher, 1985; Curlewis et al., 1988; Monfort et al., 1991). In fallow deer, multiple successive silent ovulations leading up to the start of the breeding season have been observed. The transient nature of the preliminary corpora lutea may actually serve to promote within-herd synchrony of first overt oestrus of the season (Asher, 1985). Subsequent oestrous cycles are generally of 'normal' duration, as determined genetically for each species, although occasional 'long cycles' (2-3 times normal duration) have been observed in some Pere David's deer and Eld's deer (Curlewis et al., 1988; Monfort et al., 1991). Average duration of the normal oestrous cycle ranges from 17 days in sambar deer and axis deer, 18-20 days in red deer and Eld's deer, 21-23 days in fallow deer, and 24-27 days for moose (Alces alces) and black-tailed deer (Odocoileus hemionus). The mean duration of the oestrous cycle tends to increase progressively during the breeding season in 

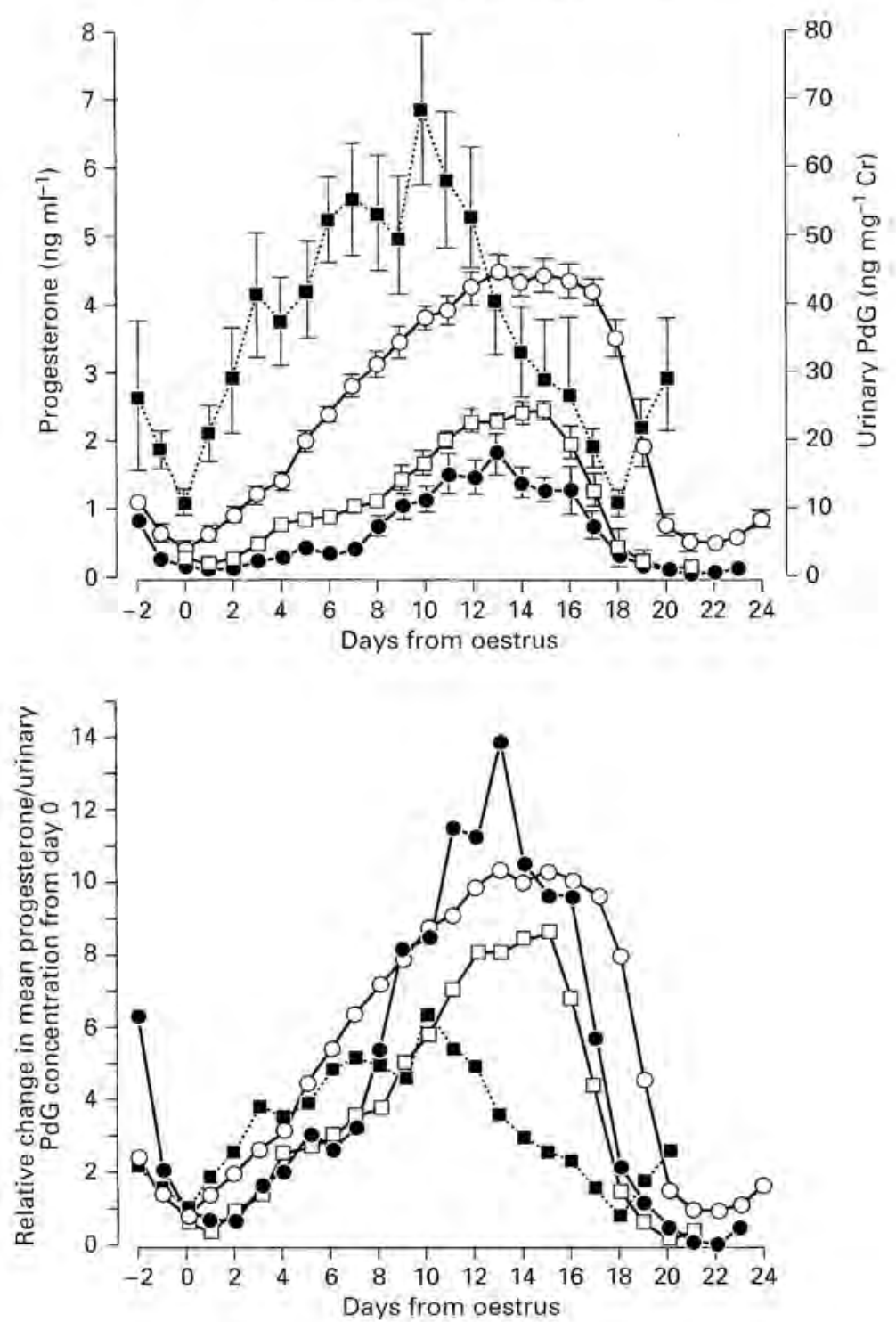

Fig. 2. Profiles of mean peripheral plasma concentrations of progesterone (solid line) or urinary concentrations of PdG (dashed line) during the cervid oestrous cycle for fallow deer $(0, n=20$ cycles), red deer $(\square, n=8$ cycles), axis deer $(-n=12$ cycles) and Eld's deer (田, $n=12$ cycles). (a) Mean ( \pm SEM) values; (b) the same data presented as relative change in mean concentrations from day 0 (data from Asher, 1985: Asher and Fisher, 1991; Monfort et al., 1991; Mylrea, 1992).

red, fallow and black-tailed deer (Guinness et al., 1971; Asher, 1985; Curlewis et al., 1988; Monfort et al., 1991; Chapple et al., 1993; Schwartz and Hundertmark, 1993; Wong and Parker, 1993).

Luteal events during the cervid oestrous cycle are similar between species (Fig. 2). Luteinization of post-ovulatory follicles is associated with increased secretion of progesterone, with maximal concentrations of peripheral blood or urinary metabolites occurring between days 10 and 16 of the 


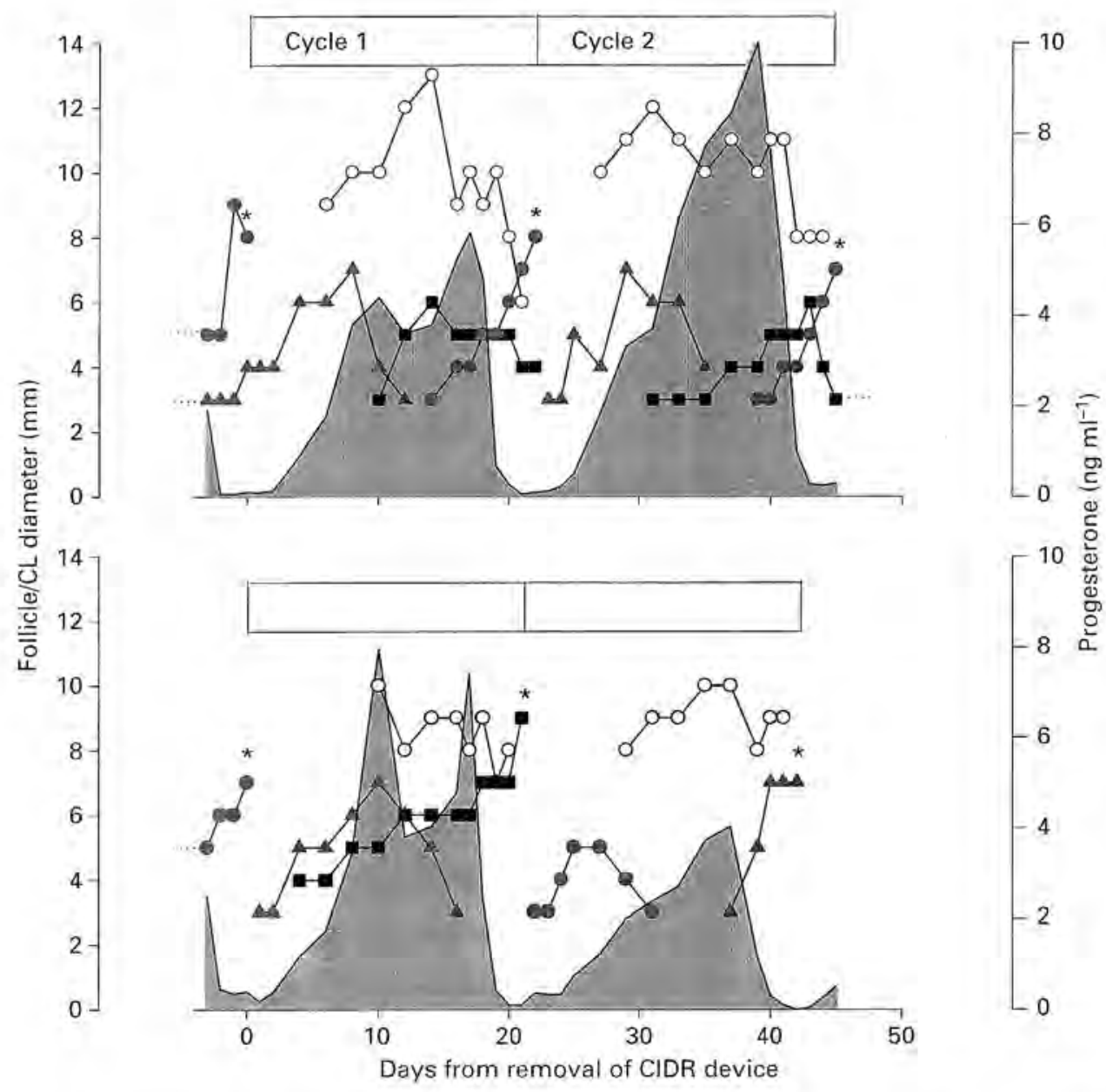

Fig. 3. Representative profile for a fallow deer doe of plasma concentrations of progesterone (shaded profiles), diameters of corpora lutea $(O)$ and diameters of dominant follicles during two consecutive luteal cycles following synchronization with a CIDR device. Asterisks denote abrupt follicular disappearance indicative of ovulation (G.W. Asher et al., unpublished).

oestrous cycle (day $0=$ oestrus). Although absolute plasma concentrations vary between species (Fig. 2a), the relative changes from day 0 are quite similar between species (Fig. 2b). Follicular dynamics during the oestrous cycle have been described from ultrasonographic studies on red deer (Asher et al., 1997b) and, more recently, fallow deer (G.W. Asher et al, unpublished). These studies have demonstrated discrete, non-random patterns of antral follicular growth and regression during the oestrous cycle. The cycle is characterized by a variable number (1-3) of dominant follicular waves (Fig. 3), similar to that observed in cattle. However, these studies relate to species that are highly seasonal breeders and strictly monovular, and may not reflect ovarian dynamics across the range of cervids.

In many respects, the cervid oestrous cycle is similar to that of other domestic ruminant species. Thus methods of artificial oestrous synchronization have tended to follow similar procedures used for sheep and cattle. These include, principally, the use of progestagens (particularly progesterone) to simulate the luteal cycle, and prostaglandins to control luteal longevity (reviewed by Asher et al., 

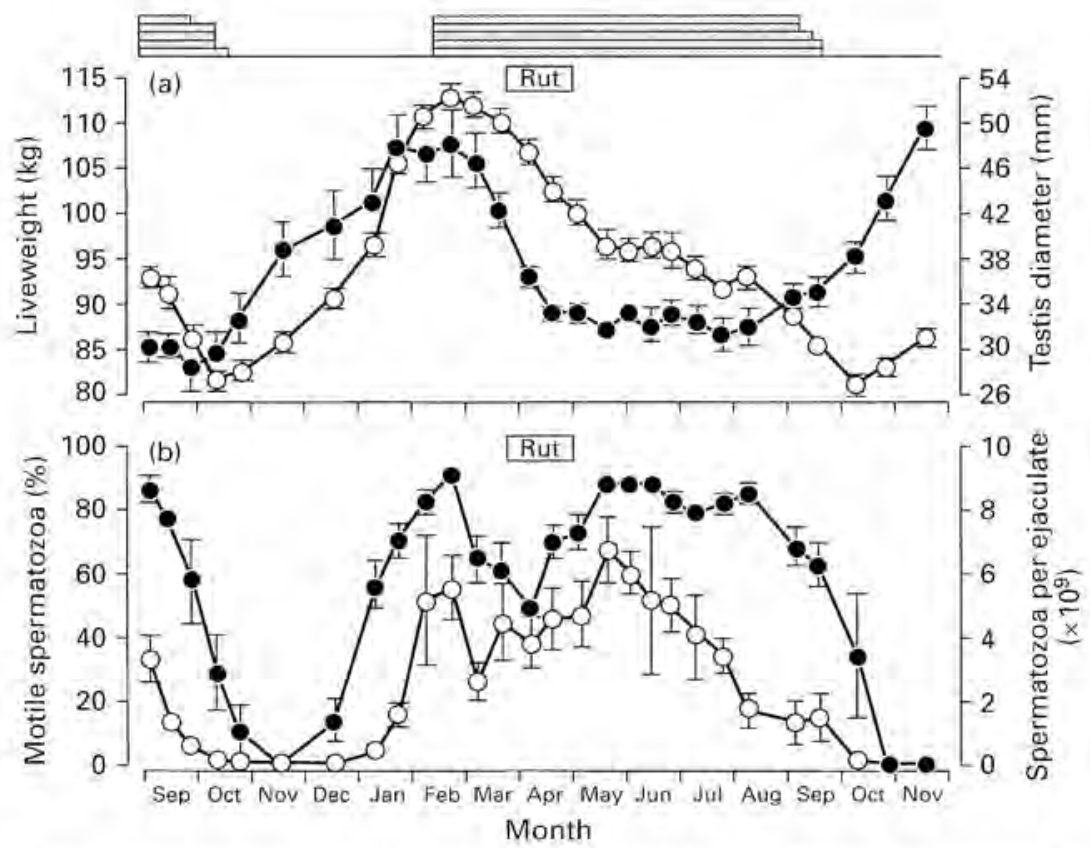

Fig. 4. Seasonal profiles of (a) mean ( \pm SEM) live weight $(-$ ), testicular diameter (O), (b) motile spermatozoa $\left(-\right.$ and spermatozoa per ejaculate $(O)$ for five $F_{1}$ hybrid Mesopotamian x European fallow deer bucks (data from Asher et al., 1996).

1993b). As a generalization, these techniques have been efficacious, leading to the development of a number of successful technologies such as artificial insemination and embryo transfer (see later).

\section{Testicular Cycles}

Circannual variation in testicular function is evident in most deer species, reflecting changes in fertility, gross morphometry and behaviour. Of the temperate species, these changes have been best described for red deer (Lincoln, 1971, 1985) and fallow deer (Asher et al., 1989; Schnare and Fischer, 1987). In the adult fallow deer buck, marked annual changes in testicular function (Fig. 4) are controlled primarily by dynamic changes in pituitary secretion of LH. LH is secreted in pulses that vary in amplitude and frequency during the year, being of low amplitude and frequency during the non-breeding season (early summer) and of high amplitude and frequency leading up to the onset of the breeding season in autumn. A similar pattern of secretion has been observed for Eld's deer, a tropical but seasonally breeding species (Monfort et al., 1993a).

Testosterone mediated changes in secondary sexual characteristics are very pronounced in both temperate and tropical cervid species. The antler cycle is linked closely to the testis cycle, with antlers cast annually when testes regress to theír minimal dimensions. Casting is in response to a marked decline in testosterone secretion and can be induced by castration (Goss, 1983). New antler growth occurs during the quiescent phase of the testes, in the relative absence of testosterone secretion. Mineralization of antlers coincides with increasing testicular activity and increasing testosterone secretion, and hard antlers are generally retained while testicular tissue is actively secreting modest to high amounts of testosterone. This relationship holds for most antlered species studied (Goss, 1983), although the seasonal patterns vary between species and antler-testis cycles may not be synchronized amongst individuals of some tropical species (Loudon and Curlewis, 1988). 
Circannual patterns of testicular regression and recrudescence occurring in temperate cervid species relate to annual cycles of sperm production. Unlike most seasonally breeding domestic ruminants, which show moderate fluctuations in testicular activity (for example sheep), temperate cervids exhibit alternating periods of sperm production and complete spermatogenic arrest that reflect about fivefold changes in seasonal testicular volume (Lincoln, 1971; Haigh et al., 1984; Gosch and Fischer, 1989). In fallow deer, for example, as testicular size increases towards the rut, there is a concomitant increase in spermatogenic activity, such that by the onset of the rut large numbers of viable spermatozoa are present in ejaculates (Fig. 4). The testes remain active throughout winter, secreting modest amounts of testosterone and producing large numbers of spermatozoa. However, towards the onset of spring, $\mathrm{LH}$ and testosterone secretion diminish and the testes regress in size. Spermatogenesis is arrested completely by early summer, and the bucks become infertile. They remain in this condition for about two months, gradually regaining fertility towards the end of summer (Fig. 4).

Although tropical cervid species often exhibit circannual cycles of reproductive development, either in a synchronous (for example Eld's deer, chital deer in Australia, Reeve's muntjac in UK) or non-synchronous manner (for example chital deer in UK), males appear to retain a degree of fertility throughout the year (Loudon and Curlewis, 1988; Chapman and Harris, 1991; Mylrea, 1992; Monfort et at., 1993a). Seasonal fluctuations in spermatogenesis are related to the stage of the antler cycle, with reduced production of spermatozoa and minimal testis size during velvet antler growth. However, at no stage is there complete arrest in spermatogenesis. For example, while male Eld's deer exhibit $80 \%$ abnormal spermatozoa as well as significantly reduced motility and total numbers of spermatozoa during the nadir of the testicular cycle, they remain effectively fertile.

The implications of the seasonal nature of spermatogenesis or fertility in male deer of most species relate mainly to the collection of semen for artificial insemination programmes and other reproductive technologies. The season of collection is clearly limited to the period of fertility, being 5-7 months in red deer and fallow deer (Asher et al., 1993b) but potentially longer in some tropical species.

\section{Assisted Reproductive Technologies (ART)}

Rapid expansion of the deer farming industry around the world within the last 20 years has been accompanied by equally rapid development and adoption of a number of assisted reproductive technologies. These technologies have not only facilitated increased rates of genetic improvement on individual farms, but also allowed widespread movement of genetic material around the world, have been implicated in genetic 'rescue' of rare genotypes or individuals, and have allowed farmers and researchers to cross species boundaries in the production of potentially useful hybrids. The principal tools that have been used include artificial insemination (AI), multiple ovulation-embryo transfer (MOET) and in vitro embryo production (IVEP). These technologies have essentially been adapted from those developed for more traditional agricultural species such as sheep and cattle. However, subtle differences in reproductive physiology between livestock species often result in major obstacles in successful application of artificial breeding techniques across species, and considerable research has been required to fine tune these technologies for deer. Even within cervids, there are considerable species and subspecies differences in the effectiveness of standardized techniques, necessitating refinements tailor-made for individual genotypes.

\section{Artificial insemination}

The development of successful AI protocols for red deer and fallow deer, including the components of semen collection and cryopreservation, oestrous synchronization and insemination technique, have been reviewed in detail by Asher et al. (1993b). In summary, most inseminations performed for these two species have involved fixed-time, laparoscopic intra-uterine deposition of 
semen that has been collected by electroejaculation. The AI procedures (with the exception of method of semen collection) are essentially similar to those used for sheep in Australasia (Killeen and Caffery, 1982). However, there are significant procedural differences for the two cervid species even though their overall reproductive physiology appears similar. For example, oestrous synchronization in red deer is improved by delivery of equine chorionic gonadotropin (eCG) towards the final phase of progesterone treatment. However, eCG is contra-indicated in fallow deer as it depresses ovulatory response in a high proportion of treated individuals (Asher et. al., 1993b). North American wapiti; a subspecies of red deer, have also received considerable attention in the development of AI protocols. Wapiti are considerably larger in body size than red deer, and it is routine practice to perform transcervical intra-uterine AI aided by rectal manipulation of the reproductive tract.

Major biological limitations to the application of AI in these species relate mainly to seasonal constraints. Efficacy of oestrous synchronization techniques improves markedly over the short (1-2 week) period representing the transition from the non-breeding season to the breeding season and remains optimal throughout the rut period (Morrow et al., 1995). Effective synchronization is achieved for the first time during the natural rut, although the additional use of eCG in sychronization programmes for red deer appears to extend this period earlier by 1-2 weeks (Asher et al., 1993b). As there are biological penalties of late calving (for example high winter mortality of calves), the consequences of a failed AI programme can be quite severe, as it inevitably delays the calving period by about 3 weeks (i.e. oestrous cycle duration). Attempts to perform AI programmes earlier in the season to compensate for this often result in poor conception rates, due to high levels of ovulatory failure.

As mentioned earlier, semen harvest from valuable sires is subject to major seasonal constraints which often conflict with the need to use their genetic material in a given season. Usable semen is seldom collected from stags or bucks more than 1-2 weeks before the natural rut. However, effective cryopreservation techniques have overcome this shortfall (Asher et al., 1993b).

\section{Multiple ovulation - embryo transfer (MOET)}

MOET technology has been developed mainly for a few cervid species that are farmed, namely red deer and fallow deer (Fennessy et al., 1994). In red deer, the efficiency of MOET approximates that of cattle in terms of surrogate pregnancies per donor. However, efficiency of MOET for fallow deer is very low by comparison (Morrow et al., 1994; Jabbour et al., 1994). This finding represents major species differences in superovulatory response to exogenous gonadotrophins and in fertilization rates of ova. Such diversity in outcomes between two species of apparently similar physiology highlights the difficulties in transferring technology across a range of cervid species. Even subspecies differences, such as that between red deer and wapiti, are associated with major differences in responses to specific exogenous gonadotrophins (Fennessy et al., 1994),

Although MOET would appear to have potential application in ex situ conservation of endangered cervid species, allowing increased numbers of progeny to be produced from a small female donor base, there are few examples amongst cervids in which a suitable surrogate (i.e. recipient species) is available. One potential case, however, is the feasibility of using European fallow deer (or hybrids) as surrogates for Mesopotamian fallow deer embryos. These two subspecies represent the extremes in conservation status, and yet are reproductively and genetically compatible (Asher et al., 1996).

\section{In vitro embryo production (IVEP)}

To date, studies have been largely confined to red deer (Fukui et al., 1991; Berg et al., 1995) and wapiti (Pollard et al. 1995). Observed difficulties in oocyte maturation, in vitro fertilization and subsequent embryo development using standard bovine and ovine systems highlight the difficulties of direct transference of technology across species. However, it is recognized that the in vitro 
technologies will eventually open up a wider range of potential applications in population and genetic management of farmed and zoo populations of cervids.

\section{Application of ART to zoo populations}

Although AI, MOET and IVEP have been heralded as tools for enhancing the captive breeding of endangered species, these assisted techniques have not yet proved to be consistently useful for producing offspring or have not been integrated effectively into captive management schemes (Wildt, 1992). One reason that these biotechniques have not yet become routine is because success is sporadic at best, due, in part, to the failure of scientists to first develop strong biological databases before artificial breeding is attempted. For AI to be successful, detailed prerequisite information must include understanding the reproductive cycle of the female to allow for identification or manipulation of oestrus or ovulation, safe and reliable methods for collecting and storing spermatozoa, and methods for proper deposition of spermatozoa at the optimal time and site in the female. Even after the capacity to produce offspring in an endangered species routinely using AJ is developed, a challenge remains: the practical demonstration that such a strategy can be implemented on a 'real-life' basis, for the betterment of regional collections and species conservation. Most zoos are ill-equipped to perform routine animal manipulations and procedures as simple as blood sampling without anaesthetizing animals. Successful production of Eld's deer offspring using AI with frozen-thawed spermatozoa provides an excellent example of how ART can be applied to an endangered species (Monfort et al., 1993b). However, it is important to emphasize that the AI study was preceded by a pre-emptive, 3 year effort to establish an integrative database for both female and male Eld's deer (Monfort et al., 1991; 1993a-d). For example, detailed information on seasonality ensured that hinds were not inseminated too early or late in the breeding season, and seasonal evaluations of ejaculates indicated the time of year most likely to result in peak sperm quality and freezability. Semen collection and cryopreservation studies were conducted to ensure that spermatozoa could be collected routinely by electroejaculation, and various cryodiluents, cryoprotectants and freezing protocols were tested to ensure that excellent motility post-thaw could be achieved. Our research verified that CIDR devices were effective for synchronizing oestrus and demonstrated that the basic AI protocol commonly used in farmed fallow deer (Asher et al., 1990) was effective in the Eld's deer. But, because most zoos do not have adequate animal handling systems, or management schemes that permit routine animal restraint or repeated anaesthesia, blood collection and ultrasonography are generally impractical. Development of biological databases for female and male Eld's deer would not have been feasible without the use of noninvasive endocrine monitoring techniques. In fact, for most species maintained in zoos, urinary or faecal steroid monitoring are the only altematives for assessing longitudinal endocrine rhythms (Lasley and Kirkpatrick, 1991; Schwarzenberger et al., 1996). These approaches provide considerable promise for improving the success rates of ART in species maintained in zoos.

\section{References}

Asher GW (1985) Oestrous cycle and breeding season of farmed fallow deer, Dama dama. foumal of Reprodiction and Fertility $75521-529$

Asher GW, Peterson AJ and Bass J (1989) Seasonal pattern of LH and testosterone secretion in adult male fallow deer, Danta dama. Journal of Reproduction and Fertility 85 657-665

Asher GW, Kraemer DC, Magyar SJ, Brunner M, Moerbe R and Giaquinto M (1990) Intrauferine insemination of farmed fallow deer (Dama dama) with frozen-thawed semen via laparoscopy Theriogenology/34 569-577

Asher GW, Fisher MW, Fennessy PE, Suttie JM and Webster JR (1993a) Manipulation of reproductive seasonality of farmed red deet (Cerous elaphis) and fallow deer (Dama dana) by strategic administration of exogenous melatonin Animal Reproduction Science 33 267-287

Asher GW, Fisher MW, Fennessy PF, Mackintosh CG, Jabbour HN and Morrow CJ (1993b) Oestrous synchuronization, semen collection and artilicial insemination of farmed red deer (Cerous elaphus) and fallow deer (Dama dama) Animtal Reproduction Science 33 241-265

Asher GW, Berg DK, Beaumont S, Morrow CJ, O'Neill KT and Fisher MW (1996) Comparison of seasonal changes in reproductive parameters of adult male European fallow deer (Dama dama dama) and hybrid Mesopotamianx European fallow deer ( $D$ d mesopotamica $\times D$ d dama) Animal Reproduction Science 45 201-216 
Asher GW, Muir PD, Semiadi G, O'Neill KT, Scott IC and Barry TN (1997a) Seasonal patterns of huteal cyclicity in young red deer (Cerous elaphus) and sambar deer (Cerous unicolor) Reproduction, Fertility and Development $9587-596$

Asher GW, Scott IC, O'Neill KT, Smith JF, Inskeep EK and Townsend EC (1997b) Ultrasonographic monitoring of antral follicle development in red deer (Cervus elaphus) Journal of Reproduction and Fertility 111 91-99

Asher BW, Scott IC, Mockett BG, O'Neill KT, Diverio S, Inskeep EK and Townsend EC (1998) Ultrasonographic monitoring of ovarian function during the oestrous cycle of fallow deer (Dana duma). Proceedings of the Fourth International Congress on the Biology of Deer, Kaposvarr, Hungary (in press)

Berg DK, Asher GW, Pugh PA, Tervit HR and Thompson JG (1995) Pregnancies following the transfer of in vitro matured and fertilised red deer (Cerous elaphus) oocytes Theriogenology 43166 (Abstract)

Blouch RA (1987) Reproductive seasonality of the white-tailed deer on the Columbian Llanos. In Biology and Management of the Cervidae pp 339-343 Ed. CM Wemmer. Smithsonian Institution Press, Washington

Branan WV and Marchinton RL (1987) Reproductive ecology of white-tailed and brocket deer in Suriname. In Biology and Management of the Cervidae pp 344-351 Ed. CM Wemmer. Smithsonian Institution Press, Washington

Chapman NG and Harris S (1991) Evidence that the seasonal antler cycle of adult Reeve's muntjac (Muntiacus reevesi) is not associated with reproductive quiescence fournal of Reproduction and Fertility $92361-369$

Chapman DI, Chapman NG and Dansie O (1984) The periods of conception and parturition in feral Reeves muntjac (Muntiacus reevesi) in southern England based upon age of juvenile animals lournal of Zoology 204 575-578

Chapple RS, English AW and Mulley RC (1993) Characteristics of the oestrous cycle and duration of gestation in chital hinds (Axis axis) Journal of Reproduction and Fertility 98 23-26

Curlewis JD, Loudon ASI and Coleman AMP (1988) Oestrous cycles and the breeding season of the Père David's deer hind (Elaphurus davidianus) Journal of Reproduction and Fertility 82 119-126

Fennessy PF, Asher GW, Beatson NS, Dixon TE, Hunter JW and Bringans MJ (1994) Embryo transfer in deer Theriogenology 41 133-138

Fukui Y, McGowan LT, James RW, Asher GW and Tervit HR (1991) Effects of culture duration and time of gondadotrophin addition on in vitro maturation and fertilization of red deer (Cerous elaplius) oocytes Theriogenology 35 499-512

Gosch B and Fischer K (1989) Seasonal changes of testis volume and sperm quality in adult fallow deer (Dama dama) and their relationship to the anfler cycle Journal of Reproduction and Feritity $857-17$

Goss RJ (1983) Deer Anilers: Regeneration, Function and Etolution, Academic Press, New York

Guinness FE, Lincoln GA and Short RV (1971) The reproductive cycle of the fernale red deer, Cervus elaphus. Journal of Reproduction and Fertility $27427-438$

Haigh JC, Cates WF, Glover GJ and Rawlings NC (1984) Relationships between seasonal changes in serum testosterone concentrations, scrotal circumference and sperm morphology of male wapiti (Cerous elaphus) Journal of Reproduction and Fertility $70413-418$

Jabbour HN, Marshall VS, Argo C McG, Hooton J and Loudon ASI (1994) Successful embryo transfer following artificial insemination of superovulated fallow deer (Dama dama) Reproduction, Fertility and Developnient 6 181-185

Jackson JE and Langguth A (1987) Ecology and status of the pampas deer in the Argentinean pampas and Uruguay, In Biology and Management of the Cervidae pp 403-409, Ed. CM Wemmer. Smithsonian Institution Press, Washington

Killeen ID and Caffery MGJ (1982) Uterine insemination of ewes with the aid of a laparoscope Australian Veierinary Journal 59 95-96

Lasley BL and Kirkpatrick JF (1991) Monitoring ovarian function in captive and free-ranging wildlife by means of urinary and fecal steroids Journal of Zoological Wildlife Medicine 22 23-31

Lincoln GA (1971) The seasonal reproductive changes in the red deer stag (Cerous elaphus) Journal of Zoology 163 105-123

Lincoln GA (1985) Seasonal breeding in deer. In The Biology of Deer Production Eds PF Fennessy and KR Drew. Bulletin No 22, Royal Society of New Zealand, Wellington 165-179

Lincoln GA and Short RV (1980) Seasonal breeding: Nature's contraceptive Recent Progress in Hormone Research 36 1-52

Loudon ASI and Curlewis JD (1988) Cycles of antler and testicular growth in an aseasonal tropical deer (Axis axis) Journal of Reproduction and Fertility 83 729-738

Marshall FHA (1937) On the change over in the oestrous cycle. in animals after transference across the equator, with further observations on the incidence of the breeding seasons and the factors controlling sexual periodicity Proceedings of the Royal Society of London Sories B $122413-428$

Mishra HR and Wemmer C (1987) The comparative breeding ecology of four cervids in Royal Chitwan National Park. In Biology and Mandgement of the Cervidae pp 259-271 Ed. CM Wemmer. Smithsonian Institution Press, Washington

Monfort SL, Wemmer C, Kepler TH, Bush M, Brown JL and Wildt DE (1991) Monitoring ovarian function and pregnancy in Eld's deer (Cervus eldi thamin) by evaluating urinary steroid metabolite excretion Joumal of Reproduction and Fertility 88 271-281

Monfort SL, Brown JL, Bush M, Wood TC, Wemmer C, Vargas A, Williamson LR, Montali R and Wildt DE (1993a) Circannual inter-relationships among reproductive hormones, gross morphometry, behaviour, ejaculate characteristics and testicular histology in Eld's deer stags (Cerous eldi thamin) Journal of Reproduction and Fertility 98 471- 480

Monfort SL, Asher GW, Wildt DE, Wood TC, Schiewe MC, Williamson L.R, Bush M and Rall WF (1993b) Successful intrauterine insemination of Eld's deer (Cerous eldi thamin) with frozen-thawed spermatozoa Journal of Reproduction and Fertility 99 459-465

Monfort SL, Brown JL and Wildt DE (1993c) Episodic and seasonal rhythms of cortisol secretion in male Eld's deer (Cerous eldi thanin) Journal of Endocrinology $13841-49$

Manfort SL, Williamson LR, Wemmer CM and Wildt DE (1993d) Intensive management of the Burmese brow-antlered deer Cervus eldi thamin for effective captive breeding and conseryation Intemational Zoology Yearbook 32 44-56

Morrow C], Asher GW, Berg DK, Tervit HR, Pugh PA, McMillan WH, Beaumont S, Hall DRH and Bell ACS (1994) Embryo transfer in fallow deer (Dama dama): superovulation, embryo recovery and laparoscopic transfer of fresh and cryopreserved embryos Theriogenology 42 579-590

Morrow CJ, Asher GW and MacMillan KL (1995) Oestrous synchronisation in farmed fallow deer (Dama dama): effects of season, treatment duration and the male on the efficacy 
of the intravaginal CIDR device Animal Reproduction Science 37 159-174

Mylrea GE (1992) Natural and artificial breeding of farmed chital deer (Axis axis) in Australia PhD thesis, University of Sydney, NSW, Australia

Pollard JW, Bringans MJ and Buckrell B (1995) In vitro production of wapiti and red deer (Cervus elaphus) embryos Theriogenology 43 301-304

Schnare H and Fischer K (1987) Secondary sex characteristics and cormected physiological values in male fallow deer (Dama dama) and their relationship to changes of the annual photoperiod: doubling the frequency journal of Experimental Zoology $224463-471$

Schwartz CC and Hundertmark KJ (1993) Reproductive characteristics of Alaskan moose Journal of Wilalife Management 57 454-468

Schwarzenberger F, Mostl E, Palme R and Bamberg E (1996) Faecal steroid analysis for non-invasive monitoring of reproductive status in farm, wild and zoo animals Antimal Reproduction Science 42 515-526

Smith TR, Hunter CG, Eisenberg JF and Sunquist ME (1996) Ecology of white-tailed deer in eastern Everglades National Park Florida Museum of Natural History 39 141-172
Thomas DC and Cowan IMcT (1975) The pattern of reproduction in female Columbian black-tailed deer, Odocoileus hemionus columbinms, journal of Reproducfion and Fertility 44 261-272

van Mourik S (1986) Reproductive performance and maternal behaviour in farmed rusa deer, (Cervus rusa timorensis) Applied Animal Behaviour Science 15 147-159

van Mourik SA and Stelmasiak T (1990) Endocrine mechanisms and antler cycles in rusa deer, Cervus (Rusa) timorensis. In Horns, Pronghorns and Antlers pp 265-297 Eds GA Bubenik and $A B$ Bubenik. Springer-Verlag, New York

Wemmer C, Halverson T, Rodden M and Portillo, T (1989) The reproductive biology of female Pere David's deer (Elaphutus drvidianus) Zoo Biology 8 49-55

Whitehead GK (1993) The Whitehend Encyelopaedia of Deer Swan Hill Press, Shrewsbury, UK

Wildt DE (1992) Genetic resource banks for conserving wildlife species: justification, examples and becoming organized on a global basis Animal Reproduction Science 28 247-257

Wildt DE, Rall WF, Critser JK, Monfort SL and Seal US (1997) Genome resource banks: 'Living collection' for biodiversity conservation Biosciénce 47 689-698

Wong B and Parker KL (1993) Estrus in black-tailed deer journal of Mammology 69 168-171 